\title{
Nonimmune Fetal Anemia: Exploring the Unfathomed! Case Series and Review of Literature
}

\author{
Nina Navakumar ${ }^{1}, \mathrm{R}_{\text {Vidyalekshmy }}{ }^{2}$, Neetha $\mathrm{A} \mathrm{Paul}^{3}$
}

\begin{abstract}
Background: To discuss a series of complex non-immune fetal anemia cases, including etiology, investigations, workup, diagnosis, and management.

Materials and methods: Five complex non-immune cases of fetal anemia seen in our department are presented.

Results: Of the five cases presented, all are live births with follow-up least up to 1.5 years of age. They are cases of hereditary spherocytosis, congenital dyserythropoietic anemia, MCDA twins-twin-twin transfusion syndrome (TTTS) post-laser co-twin demise-fetal anemia, placental chorioangioma, and massive fetomaternal hemorrhage.

Conclusion: Non-immune causes of fetal anemia can be difficult to diagnose its etiology and hence complex to manage. Repeated intrauterine transfusions may be the only perinatal management. The perinatal morbidity/mortality and preterm delivery rates are increased, and some cases require long-term treatment including regular transfusions. We present our experience of a series of complex non-immune fetal anemia managed in a tertiary unit, review the literature, and suggest appropriate management.

Keywords: Fetal anemia, Fetal blood sampling, Intrauterine transfusion, Non-immune hydrops.

International Journal of Infertility and Fetal Medicine (2020): 10.5005/jp-journals-10016-1198
\end{abstract}

\section{BACKGROUND}

Fetal anemia is a rare and life-threatening condition for the developing fetus. ${ }^{1}$ As fetal hemoglobin $(\mathrm{Hb})$ values increase gradually with advancing gestation, anemia may be classified based on the degree of $\mathrm{Hb}$ deviation from the mean for gestational age (GA) or on multiples of the median (MoM) for GA. 'Hydrops usually does not develop until the $\mathrm{Hb}$ deficit is $>70 \mathrm{~g} / \mathrm{L}$ or the absolute $\mathrm{Hb}$ value is $<50 \mathrm{~g} / \mathrm{L}$ or fetal hematocrit $<30 \%$. $^{2}$ It can be due to many causes of which RBC-Rh alloimmunization is the most common. Fetal anemia occurs as a fetal manifestation due to an underlying etiology which is difficult to diagnose prenatally and needs a multidisciplinary team approach for a precise diagnosis and appropriate parental counseling. With the advances in obstetric ultrasound, it permits accurate noninvasive screening of fetal anemia by measurement of the middle cerebral artery peak systolic velocity (MCA-PSV), replacing serial amniocentesis. . $^{3,4}$ Ultrasound screen positive fetal anemia followed by fetal blood sampling (FBS) and intrauterine transfusion (IUT) techniques has resulted in almost $90 \%$ survival of anemic fetuses, with good long-term neurodevelopmental outcomes. ${ }^{2}$

\section{Etiological Classification-Immune and Non-immune Causes}

Immune causes can be due to RBC alloimmunization-Rh blood group (D, C, C, e, E), Kell, Duffy, Kidd, or any IgM RBC antibody.

Non-immune causes can be due to congenital infections (parvovirus B19, cytomegalovirus, toxoplasmosis, syphilis), inherited anemias (hemoglobinopathies like a-thalassemia major, RBC membrane or enzyme disorders like G6PD deficiency or pyruvate kinase deficiency), aneuploidy, bone marrow (BM) disorders [Fanconi anemia, Diamond-Blackfan anemia, congenital dyserythropoietic anemia (CDA)], hematopoietic malignancies (congenital leukemia, transient myeloproliferative disorder), fetal \begin{tabular}{l}
\hline${ }^{1-3}$ Department of High Risk Obstetrics and Fetal Medicine, Kerala \\
Institute of Medical Sciences, Trivandrum, Kerala, India \\
Corresponding Author: Nina Navakumar, Department of High \\
Risk Obstetrics and Fetal Medicine, Kerala Institute of Medical \\
Sciences, Trivandrum, Kerala, India, Phone: +919895425112 , e-mail: \\
ninanavakumar@yahoo.co.in \\
How to cite this article: Navakumar N, Vidyalekshmy R, Paul NA. \\
Nonimmune Fetal Anemia: Exploring the Unfathomed! Case Series \\
and Review of Literature. Int J Infertil Fetal Med 2020;11(1):20-26. \\
Source of support: Nil \\
Conflict of interest: None
\end{tabular}

or placental tumors, vascular malformations, other placental pathology (sacrococcygeal teratoma, liver hemangioma, hepatoblastoma, diffuse neonatal hemangiomatosis, placental chorangioma, fetal or placental arteriovenous malformations and placental mesenchymal dysplasia), fetomaternal hemorrhage (FMH) due to placental abruption, trauma, rare genetic disorders, lysosomal storage disorders (e.g., Niemann-Pick, Gaucher disease, mucopolysaccharidosis), neonatal hemochromatosis, complications of monochorionic placentation-twin anemia polycythemia sequence (TAPS), co-twin demise, twin-twin transfusion syndrome (TTTS). ${ }^{2,5}$

\section{Approach to Fetal Anemia \\ Maternal}

Family and pregnancy history (e.g., ethnicity, consanguinity, genetic syndromes, infection exposure, and trauma), complete blood count, blood group and screen (indirect Coombs titer if antibody screen+), Kleihauer-Betke test, flow cytometry, $\mathrm{Hb}$ electrophoresis, and serologies [PB-19 IgG and IgM, CMV IgG and IgM (avidity testing if $\lg M+)$, toxoplasmosis $\lg G$ and $\lg M$, syphilis testing]. ${ }^{2}$ 


\section{Fetal}

Detailed fetal structural evaluation and placental ultrasound, MCA-PSV Doppler, fetal echocardiogram if hydrops, FBS, blood type, $\mathrm{Hb}$, hematocrit, platelet count, direct Coombs, reticulocyte count and total bilirubin, PCR for CMV and PB 19 with or without syphilis and toxoplasmosis, peripheral smear, nonstress test for sinusoidal fetal heart rate pattern. ${ }^{2}$

\section{Approach to Rare Causes of Fetal Anemia}

Genetic counseling, parental-Hb, high-performance liquid chromatography and RBC enzyme assays (i.e., pyruvate kinase, G6PD), fetal-peripheral smear, Hb electrophoresis, and chromosome fragility studies (i.e., Fanconi anemia). If elevated white blood cell count-differential and peripheral smear to rule out congenital leukemia or transient myeloproliferative disorder. ${ }^{2}$

\section{Sonographic Features of Fetal Anemia}

The general survey, evaluate for secondary causes (i.e., fetal or placental) of anemia, hydrops, ascites, placentomegaly (placental thickness $>2$ SD above GA mean 28 or $>18 \mathrm{~mm}$ at $12-15$ weeks or $>30 \mathrm{~mm}$ at $18-21$ weeks), cardiomegaly: CTR $>0.5$ before 18 weeks or $>0.52$ after 18 weeks and congenital infectionsplacentomegaly, hepatosplenomegaly, echogenic bowel, liver calcifications, ventriculomegaly, intracranial calcifications, and growth restriction. Complications of monochorionic twinsTAPS discordant MCA-PSV (>1.5 MoM in donor and <0.8 MoM in recipient), discordant placental echogenicity, "starry sky" appearance of the liver in recipient, and specific clinical condition, such as, a-thalassemia major. ${ }^{2}$

\section{Diagnosis}

The MCA-PSV does not have a strong correlation with fetal $\mathrm{Hb}$ concentration but the decrease in fetal $\mathrm{Hb}$ level can be determined by MCA-PSV., ${ }^{6,7}$ The sensitivity of a single value of MCA-PSV is reported to be nearly $100 \%$ for moderate or severe anemia with a false-positive rate of $12 \%{ }^{1}$ The serial monitoring of the MCA-PSV may decrease the false-positive rate to $<5 \%$. ${ }^{7}$ Middle cerebral artery peak systolic velocity $>1.5 \mathrm{MoM}$ of gestation is suggestive of fetal anemia and is an indication to do FBS and IUT (Figs 1 to 3 ).

The fetal anemia is diagnosed by FBS and is reported to have a fetal loss rate of $1-2 \%$ but is seen more with earlier gestations and in presence of hydrops. ${ }^{5}$

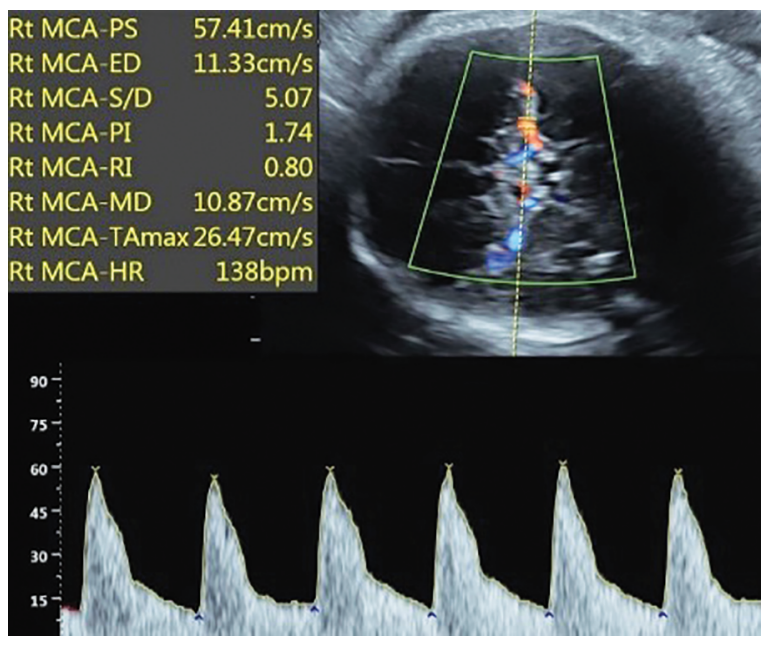

Fig. 1: Normal MCA-PSV image
In fetuses at risk of fetal anemia, MCA-PSV monitoring is ideally started from 18 to 20 weeks of gestation as it provides technical consideration to perform FBS and IUT. After 20 weeks of gestation, routine testing is usually done on a fortnightly basis but may be done more frequently with higher MoM levels or other abnormal ultrasound findings that are suggestive of developing anemia. ${ }^{6}$

\section{Management}

\section{Intrauterine Blood Transfusion (IUT)}

Intrauterine transfusion is indicated in moderate to severe anemia when the $\mathrm{Hb}$ level is $<10 \mathrm{~g} / \mathrm{dL}$ or hematocrit $<33 \%$. $^{2}$ Intrauterine transfusion can be intravascular or intraperitoneal of which intravascular is commonly used and intraperitoneal is reserved for extreme preterm cases.

Blood used for IUT is O negative freshly prepared gammairradiated CMV-negative triple packed to a hematocrit of $75 \%$ and is leukocyte depleted. It is done under aseptic conditions with ultrasound guidance using a 20-22 G needle. Fetal movement needs to be paralyzed with intramuscular or intravenous (umbilical vein) injection of atracurium or vecuronium. A needle is inserted into the umbilical vein preferably at placental cord insertion than a free loop of cord to avoid complications of arterial injury.

Once the needle is inserted into the umbilical vein FBS is sent to the laboratory for the above-mentioned tests after ensuring the needle is within the umbilical vein and not in the Wharton's jelly. The volume of blood to be transfused is determined by standard formulas to achieve the final target hematocrit of $45 \% .{ }^{5,8}$ The volume of blood to be transfused depends on donor hematocrit, fetal pretransfusion, and target $\mathrm{Hb} /$ hematocrit. $^{4}$

Volume of blood needed for IUT:

- Intravascular transfusion (IVT) $=(($ target $\mathrm{Hb}-$ fetal $\mathrm{Hb}) \times$ fetoplacental blood volume)/(donor $\mathrm{Hb}$ - target $\mathrm{Hb}$ );

- Intraperitoneal transfusion (IPT) $=($ GA in weeks -20$) \times 10 \mathrm{~mL}^{2}$

The need for repeat IUT is assessed by MCA-PSV measurement post-transfusion though its false-positive rate increases after repeated transfusions and after 34-35 weeks of gestation as fetal RBCs are replaced by adult RBCs. In general, repeat IUTs are planned based on the anticipated decline in fetal $\mathrm{Hb}$ (e.g., using $0.4,0.3$, and $0.2 \mathrm{~g} / \mathrm{L} / \mathrm{day} \mathrm{Hb}$ decline for the first, second, and third IUT intervals, respectively, or a decline of $1 \% /$ day in fetal hematocrit, as well as on MCA-PSV measurements). ${ }^{8}$

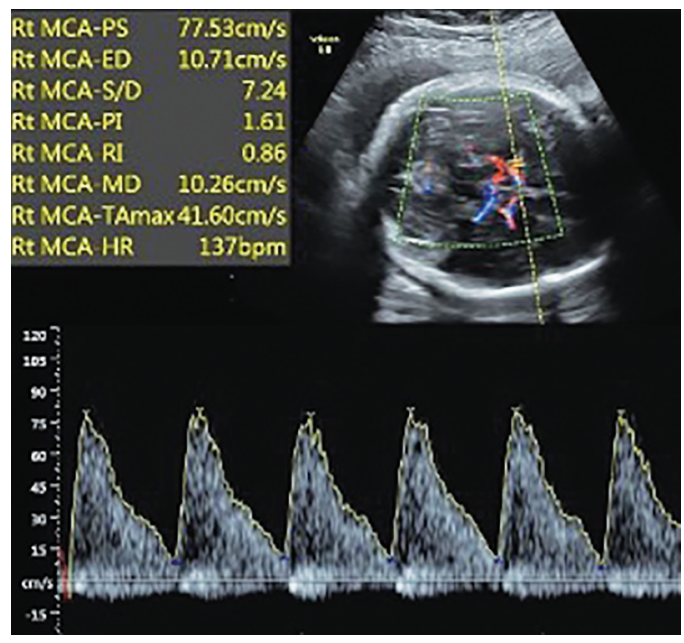

Fig. 2: Fetal anemia (MCA-PSV >1.5 MoM) 


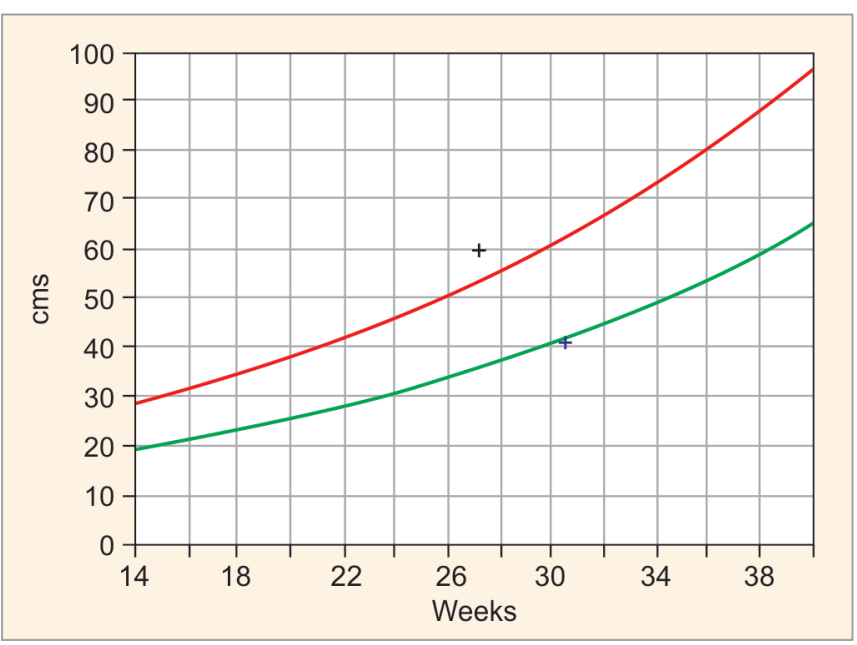

Fig. 3: Fetal anemia (MCA-PSV >1.5 MoM)

Complications reported are fetal loss rate of 1-2\%, rupture of membranes, infection, bleeding, and cord hematoma. As some complications need emergency cesarean delivery of a viable fetus, IUT has to be done in a place with immediate access to such facilities as NST (FHR monitoring), operation theater. In previous studies, overall live birth rate was reported to be $95.5 \% .^{9}$ On a long-term basis, neurodevelopmental impairment and early onset cardiovascular diseases in adulthood are studied.

Other options are intraperitoneal transfusion for extremely preterm cases ( $<22$ weeks) and hydropic fetuses, exchange transfusion, partial exchange transfusion, and intravenous immunoglobulin therapy though effectiveness not proven yet. $^{8}$

\section{Delivery}

Timing of delivery is scheduled in such a way to avoid prematurity and to deliver newborns with no or moderate anemia, not needing exchange transfusions, or prolonged phototherapy. In a pregnancy complicated by fetal anemia, with a stable fetus who has received serial IUTs, most clinicians would consider the last transfusion not later than 34-35 weeks, aiming to deliver the baby at 37-38 weeks. ${ }^{8}$ If planning for preterm delivery $<34$ weeks of gestation have to offer antenatal corticosteroid coverage. Regarding the mode of delivery, the cesarean section is considered only for obstetric indications. Newborns who had multiple transfusions will often have suppressed reticulocytes and may need top-up transfusions until hematopoiesis resumes. ${ }^{5}$

\section{Case Scenarios and their Discussions}

\section{Case 1}

A 23-year-old second gravida of Rh-positive blood group in a consanguineous marriage, presented at 12 weeks in fetal medicine unit (FMU) with a history of non-immune hydrops and severe fetal anemia resulting in neonatal death on day 1 in the previous pregnancy. NT scan and anomaly scan were normal; and FTS was low risk. At 22 weeks, scan showed fetal biometry less than 5th centile, MCA-PSV of 1.8 MoM suggestive of fetal anemia along with cardiomegaly, pericardial effusion, and scalp edema suggestive of non-immune hydrops fetalis. Because of nonimmune hydrops with fetal anemia, intrauterine blood transfusion was done. Pretransfusion values were $\mathrm{Hb} 3.6 \mathrm{~g} \%$, MCA-PSV of 1.8
MoM. Post IUT of $60 \mathrm{~mL}$, values were $\mathrm{Hb}-16 \mathrm{~g} \%$, MCA-PSV of 1.22 MoM. Maternal blood was sent for TORC panel, and baseline wok up investigations. Fetal blood sampling was done for $\mathrm{Hb}$, hematocrit, blood grouping with $\mathrm{Rh}$ typing, $\mathrm{Hb}$ electrophoresis, and karyotyping of which fetal karyotype was normal. On the next day of transfusion, MCA-PSV was measured to be $0.8 \mathrm{MoM}$. She was followed up and screened every 5 days then every weekly and later fortnightly. At 32 weeks of gestation because of MCA-PSV of 1.5 MoM (fetal anemia), antenatal corticosteroid was given and delivered a live female baby of birth weight- $1.2 \mathrm{~kg}$ by LSCS. The neonatal period baby was found to have non-immune hemolytic anemia, neonatal jaundice, and hepatosplenomegaly. Double volume exchange transfusion was done on the first day of life for $\mathrm{Hb}$ of $6.5 \mathrm{~g} \%$ and a total bilirubin level of $7.14 \mathrm{mg} / \mathrm{dL}$ followed by intensive phototherapy for 5 days. Subsequently, baby had received 1-pint PRBC transfusion on day 22 of life for $\mathrm{Hb} 7.6 \mathrm{~g} / \mathrm{dL}$ and another pint of PBC on day 26 of life. Genetic workup (exome sequencing) done for evaluation of non-immune hemolytic anemia showed homozygous mutation for hereditary spherocytosis (HS). Now the baby is on monthly blood transfusion and planned for splenectomy at 5 years of age.

\section{Hereditary Spherocytosis}

Hereditary spherocytosis, which is the most common form of inherited hemolytic anemia, occurs due to a structural defect in the RBC membrane. It occurs mostly as an autosomal dominant inheritance (mild-moderate anemia) and rarely as an autosomal recessive inheritance (fetal anemia and hydrops fetalis). ${ }^{10,11}$

Regarding our case, anemia had not been previously diagnosed in either the mother or father. Parental complete blood cell counts revealed normal $\mathrm{Hb}$, hematocrit, $\mathrm{RBC}$ indices, and platelet count. Furthermore, both parental peripheral blood smears showed normal RBC, platelet, and WBC morphology and no spherocytes were noted. Thus, autosomal dominant HS was ruled out as a potential etiology. Due to the consanguinity of the parents, autosomal recessive disorders that may lead to severe fetal anemia should always be evaluated no matter how rare.

Heterozygous autosomal recessive carriers of HS with SPTA1c.6154delG genetic mutation will produce an adequate amount of a-spectrin and are asymptomatic with normal RBC indices and no spherocytes on the peripheral blood smear. ${ }^{12,13}$ After identification of our infant's genetic mutation, both the mother and father are obligate carriers of the SPTA1 mutation. Future offspring have a $25 \%$ risk of inheriting $\mathrm{HS}$ and they may also present with severe fetal anemia and non-immune hydrops fetalis requiring fetal IUT. It is suspected that the couple's previous fetal demise also suffered from $\mathrm{HS}$

In conclusion, our case highlights a genetic mutation of the SPTA1 gene which in the homozygous state leads to severe fetal anemia and NIH that requires fetal IUT for fetal survival. Rare autosomal recessive disorders of the RBC membrane should be included in the differential diagnosis for $\mathrm{NIH}$, especially in patients with consanguinity.

\section{Case 2}

A 28-year-old woman in her fourth pregnancy was referred to our hospital at 27 weeks as a case of non-immune fetal hydrops. She had an obstetric score of G4P2L0A1IUD2 with the previous two pregnancy losses at 36 and 21 weeks due to recurrent abruptio placenta. 
A scan at our department at 27 weeks of gestation showed placentomegaly, fetal anemia (MCA-PSV of 2.2 MoM), cardiomegaly, pericardial effusion, and ascites suggestive of non-immune fetal hydrops. Baseline maternal workup did not show any abnormality in the TORC panel, indirect Coombs test, and $\mathrm{Hb}$ electrophoresis. Fetal blood sampling confirmed fetal anemia with pretransfusion $\mathrm{Hb}$ of $4 \mathrm{~g} \%$. After a course of antenatal corticosteroid intrauterine blood transfusion was done with $35 \mathrm{~mL}$ of blood into the intrahepatic vein. Fetal blood sampling showed normal fetal blood investigation and karyotype. On the next day of transfusion, the scan showed persisting fetal anemia with increasing pericardial effusion and poor myocardial contractility. Emergency LSCS was done at 27 weeks 5 days of gestation because of worsening fetal status and delivered a live preterm female baby of weight $920 \mathrm{~g}$. The liquor was meconium stained and the placenta showed hyperplacentosis. Neonatally severe anemia was managed with multiple blood transfusions and thorough evaluation for anemia was done. Clinical exome sequencing revealed CDA type I. The baby had a stormy NICU course due to extreme prematurity and anemia along with its complications and was discharged after 2 months of hospital stay. The baby was, later on, followed up with $\mathrm{Hb}$ which was found to be maintained.

\section{Congenital Dyserythropoietic Anemia}

Congenital dyserythropoietic anemia is a rare autosomal recessive disorder that causes dyserythropoiesis and iron overload. Bone marrow study reveals abnormalities in red cell precursors including multinucleated erythroblasts and chromatin bridges. Dysmorphisms, such as, distal limb abnormalities, skin pigmentation defects, vertebral malformations, and short stature may also be present. Mutations in the codanin-1 gene result in the majority of CDA type I cases. ${ }^{14}$ Laboratory findings, characterization of erythrocytes, and BM observation are diagnostic.

To diagnose prenatally at-risk pregnancies needs index child and parental work up with conformed genetic diagnosis by gene mutation analysis. Prenatally affected fetuses may present with early onset anemia, non-immune fetal hydrops to mild neonatal jaundice and anemia. Prenatally diagnosed fetal anemia requires IUT followed by postnatal transfusion dependence; splenectomy has to be considered as a palliative treatment.

Congenital dyserythropoietic anemia type I also causes nonhematological manifestations, especially skeletal, nail, and skin abnormalities are more common in CDA-I, and their presence in infants with unexplained anemia should raise suspicion for the diagnosis. The availability of molecular testing has significantly accelerated the diagnosis. Management of patients with CDA-I requires a multidisciplinary approach from an early age to improve outcomes. $^{15}$

\section{Case 3}

A 26-year-old second gravida with previous uneventful pregnancy was referred to our department at 25 weeks because of raised maternal serum alpha-fetoprotein (MSAFP) and polyhydramnios. Fetal medicine unit scan showed a normally grown fetus with no anomalies having polyhydramnios, MCA-PSV was 1.5 MoM (fetal anemia), and an echogenic lesion in the placenta measuring 6.6 $\times 5 \times 4 \mathrm{~cm}$ with color Doppler showing vascularity by a feeder blood vessel suggestive of placental chorangioma. Fetal blood sampling confirmed fetal anemia and hence was proceeded with IUT. Posttransfusion MCA-PSV was 0.8 MoM. The patient was followed up with liquor volume and MCA-PSV after 2 days and thereafter weekly. Middle cerebral artery peak systolic velocity remained $<1.5$ MoM throughout but at 31 weeks scan showed polyhydramnios. She developed preterm labor at 33 weeks and delivered a live female baby of $2.045 \mathrm{~kg}$ by vaginal delivery after a course of betamethasone for fetal lung maturity. Neonatal period was uneventful. Placental chorioangioma was confirmed in the placental gross examination and histopathological examination.

\section{Placental Chorioangioma}

Placental chorioangiomas have a prevalence of $0.5-1.0 \% .^{16}$ and are found to be the most common placental benign tumor. As they are small they are mostly diagnosed incidentally by scan and are seen more in multiple pregnancies and female babies. ${ }^{17}$ Its complications are fetal anemia, secondary to fetal hemorrhage or consumption, and destruction of fetal RBCs within the marrow, thrombosed vasculature of the chorangioma, polyhydramnios, non-immune hydrops fetalis, abruption, preterm labor, IUGR and preeclampsia, postpartum hemorrhage particularly if tumors are $>4 \mathrm{~cm}$ (Figs 4 and 5). ${ }^{18}$

It is seen in ultrasound as hypo- or hyperechoic circumscribed mass-different from placenta with anechoic cystic areas may or may not present as fetal anemia. ${ }^{19}$ Large lesions may be seen as fibrous septa, complex mass protruding into the amniotic cavity from the fetal surface near the cord insertion.

It is diagnosed by color Doppler as anechoic cystic areas with the pulsatile flow on spectral analysis; due to vascular channels demonstrating blood flow within the lesion; distinguishes chorioangioma from a placental hematoma. ${ }^{20}$

It has to be differentiated from a partial hydatidiform mole, placental hematoma, fetal sacrococcygeal teratoma, and placental mesenchymal disease. The majority of them are asymptomatic and can be managed expectantly with every 4 weekly scan follow-up while large tumors need frequent scan follow-up every 1-2 weekly. Prenatal intervention options include serial fetal transfusions (Zalel Y), fetoscopic laser coagulation of feeder vessels, chemosclerosis with absolute alcohol and endoscopic surgical devascularization. ${ }^{21}$ Spontaneous infarction within tumor results in improved outcomes while large or multiple chorioangiomas are associated with maternal and fetal complications (30-50\%).

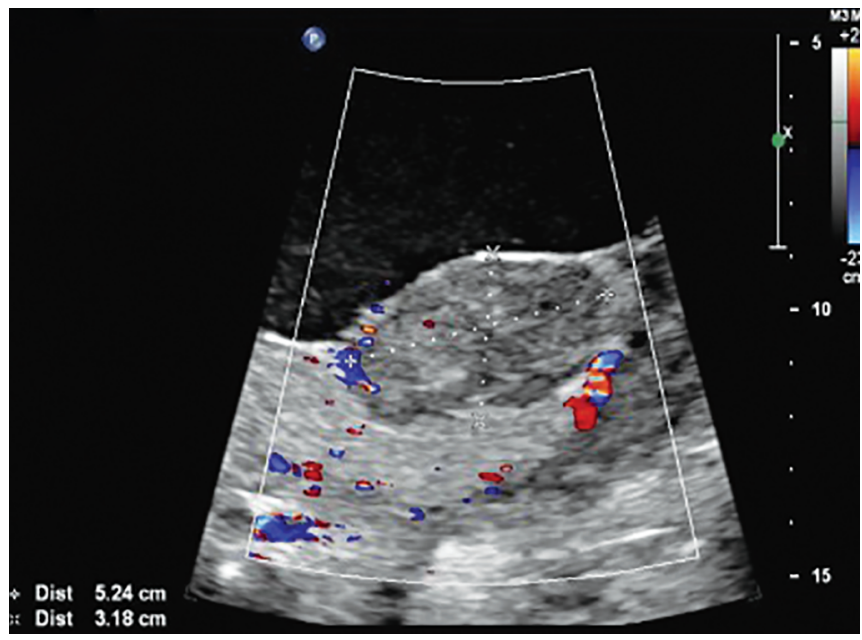

Fig. 4: Placental chorioangioma-fetal ultrasound $2 \mathrm{D}$ grayscale image with Doppler 


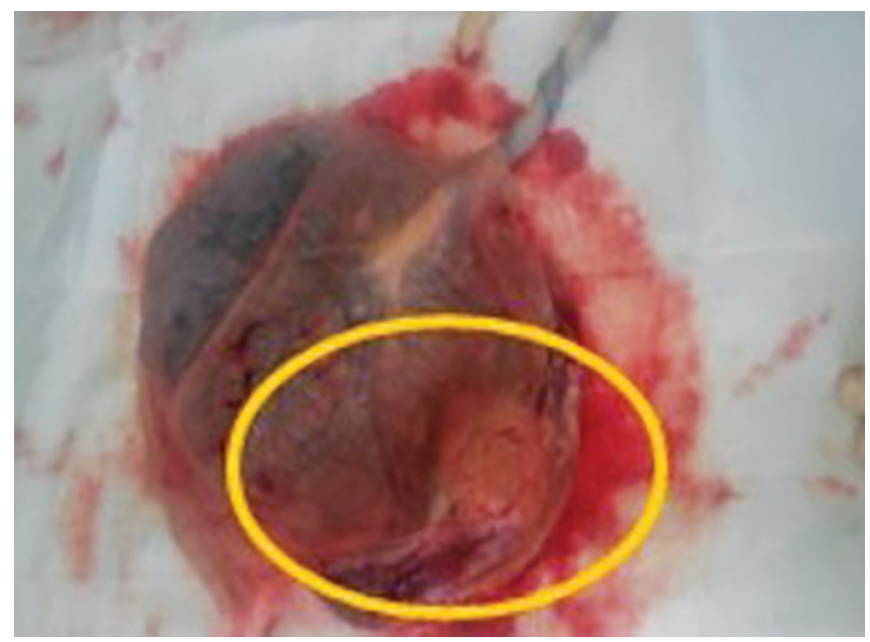

Fig. 5: Placental chorioangioma

\section{Case 4}

A woman in her second pregnancy (previously uncomplicated singleton pregnancy and healthy baby) with monochorionic diamniotic (MCDA) twins by spontaneous conception presented to our department at 24 weeks of gestation with TTTS stage 2 following which she underwent amnioreduction and was monitored weekly. At 25 weeks, scan showed progression of stage 2 TTTS to stage 3 and hence laser coagulation was done. Post laser ultrasound at 27 weeks showed intrauterine fetal demise of donor twin and moderate MR in surviving twin. After detailed counseling regarding the neurological risks of surviving twin family opted to continue the pregnancy and was monitored with weekly ultrasound to look for fetal anemia. At 31 weeks, scan showed moderate MR/ TR, pericardial effusion, and MCA-PSV of 1.7 MoM suggestive of fetal anemia. After a course of antenatal corticosteroids delivered a live male baby of weight $1.55 \mathrm{~kg}$ and a macerated IUFD male baby by LSCS, liquor was meconium stained, monochorionic placenta delivered in toto. A newborn evaluation was done for anemia and managed with blood transfusion following which $\mathrm{Hb}$ picked up to normal levels and was maintained. The neonatal neurosonogram did not reveal any abnormalities. The baby was discharged from NICU after prematurity management and care.

\section{Monochorionic Diamniotic (MCDA) Twins-Twin to Twin Transfusion Syndrome (TTTS) Post-LASER Resulting in Fetal Anemia due to Co-twin Demise}

Twin-twin transfusion syndrome occurs in up to $15 \%$ of MCDA twin pregnancies and is due to the unbalanced unidirectional placental blood flow through the arterio-venous anastomoses. ${ }^{22}$ It results in oliguric oligohydramnios in the donor and polyuric polyhydramnios and volume overload in the recipient, causing hydrops due to right ventricular dysfunction. ${ }^{23,24}$ Early stages of TTTS (stages 1 and 2) are managed conservatively by amnioreduction and or septostomy while advanced stages of TTTS (stages 3 and 4) are managed by laser photocoagulation of abnormal anastomoses or radiofrequency ablation.

Fetoscopic laser photocoagulation (FLP) was done as a definitive treatment in our case as she was within 26 weeks of gestation and it was progressive TTTS of stage 3. It is reported that after FLP survival rate of both twins is $70 \%$, one of the twins is $90 \%$, and 11 to $14 \%$ is at risk of long-term neurodevelopmental impairment. ${ }^{25}$

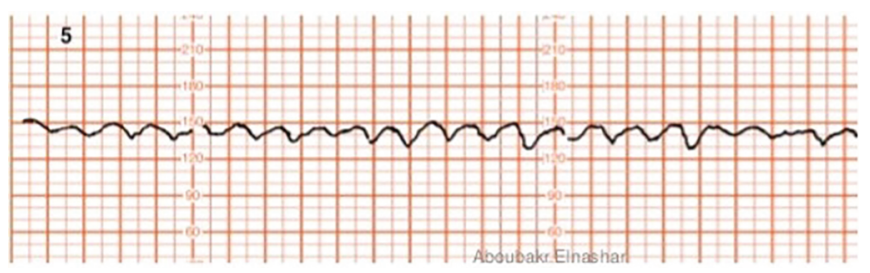

Fig. 6: Nonstress test showing sinusoidal FHR pattern

Death of one twin may occur due to hemodynamic imbalance from an acute shift of blood from the survivor to the dead twin via the placental anastomoses in monochorionic placenta, resulting in anemia, preterm birth (60-70\%), neurological handicap ( $\geq 25 \%)$, or death (15\%) of the remaining twin. ${ }^{26}$ Once the death of one twin happens further management depends on GA ( $<$ or $>24$ weeks), death at $<48$ hours or earlier, MCA-PSV value in MoM, presence of polyhydramnios and fetal MRI brain imaging findings after 4 weeks of death or at 32 weeks to rule out brain damage as per fetal medicine foundation recommendations. From previous studies, it is not known whether IUT can have an impact on neonatal or neurodevelopmental outcomes.

\section{Case 5}

A 43-year-old elderly primigravida of Rh-positive blood group with ICT negative, ICSI conception (donor ovum), case of type II DM on insulin had normal NT scan (FTS was low risk), anomaly scan, and fetal echocardiography. Growth scan at 34 weeks of gestation showed small for GA baby with oligohydramnios, fetal anemia with MCA-PSV of 1.8 MoM, pericardial effusion, and tricuspid regurgitation with normal contractility of the fetal heart. She gave a history of decreased fetal movements and NST was non-reassuring. Hence, delivered a male baby of weight- $1.9 \mathrm{~kg}$ by emergency LSCS who cried soon after birth. Neonatal examination revealed severe pallor and bradycardia. Neonatal $\mathrm{Hb}$ was- $3.9 \mathrm{~g} \%$, retic count$22 \%$ with PCV-13.5, and platelet count-29,000 cells $/ \mathrm{mm}^{3}$ of blood (thrombocytopenia). Peripheral smear showed macrocytic anemia with erythroblastemia. Viral PCR for parvovirus was negative and placental examination did not reveal any abnormality. Neonatal echocardiogram showed a structurally normal heart. Exchange transfusion was done and $\mathrm{Hb}$ picked up to $19.5 \mathrm{~g} \%$. DCT-weakly positive but Kleihauer-Betke test was negative. Preterm newborn evaluation of anemia did not reveal any direct cause, hence the cause of anemia was assumed to be due to $\mathrm{FMH}$ with negative KBT/unexplained.

\section{Fetomaternal Hemorrhage}

Incidence- 0.3 to 1 in 1,000 births. $^{27}$

Fetomaternal hemorrhage allows blood from fetal circulation to enter maternal circulation due to a break in the placental barrier. It may be due to many reasons, including intrauterine fetal demise and trauma. In $40 \%$ of cases, it is due to trauma, more with coagulopathies, high-force trauma, blunt force trauma, abdominal trauma, and anterior placental placement in the uterus. ${ }^{28}$ Though it may present as neonatal anemia to intrauterine demise it is difficult to diagnose prenatally. Severe FMH is a fatal condition and has been estimated to cause up to $14 \%$ of fetal deaths and $\mathrm{FMH}$ is a cause of stillbirth in 3-14\% of cases (Fig. 6). ${ }^{29}$

Fetomaternal hemorrhage can be diagnosed antenatally by a history of decreased or absent fetal movements, NST showing sinusoidal heart rate pattern and MCA-PSV >1.5 MoM; postnatally 
by KBT showing fetal cells in the maternal circulation. ${ }^{30}$ When the mother presents with reduced fetal movements or abdominal trauma we need to evaluate with NST, ultrasound evaluation of fetal size, biophysical profile and amniotic fluid volume and MCAPSV. ${ }^{31}$ Middle cerebral artery peak systolic velocity may be useful to predict fatal obstetric complications of FMH and help in timely and effective management. ${ }^{30}$

KBT has low sensitivity and high specificity, with a threshold of at least $5 \mathrm{~mL}$ of FMH to be positive. Only $0.01 \mathrm{~mL}$ is required to cause isoimmunization. As such KBT is a test to determine the amount of FMF and not to determine whether FMF is present which implies that FMF may be present even if KBT is negative. If KBT is positive it can be used to calculate additional RhoGAM dosing over the standard 150 or $300 \mu$ g dosage. ${ }^{28}$

\section{Conclusion}

Noninvasive MCA-PSV Doppler predicts fetal anemia accurately. A clear-cut algorithmic approach for fetal anemia especially for non-immune causes of fetal anemia is difficult to define. Once fetal anemia is identified from ultrasound, first step is to rule out immune causes with a negative indirect Coombs test and then TORCH serology to rule out fetal infections, following which rare causes of fetal anemia have to be considered. Further workup includes thorough history, detailed fetal ultrasound, maternal and fetal investigations. In FBS, confirmed fetal anemia IUT is done as a lifesaving procedure in most of the cases which helps to reduce perinatal morbidity and mortality and to plan timely delivery.

\section{Clinical Significance}

Fetal anemia is a rare but serious condition. Immune fetal anemia is most common mostly due to RBC alloimmunization. With the advent of anti $D$ injection, the immune fetal anemia cases are on a decreasing trend. Non-immune causes are a challenge for the prenatal diagnosis and a specific diagnosis warrants extensive work up in the mother as well as in the fetus, still some cases remain unexplained. Middle cerebral artery peak systolic velocity Doppler for prediction of fetal anemia is noninvasive and accurate with a sensitivity of $95 \%$. With FBS and IUT, fetal survival has been reported at 85 to $90 \%$ and in our study it is $100 \%$ among non-immune fetal anemia for those whom it was done.

\section{Acknowledgments}

We acknowledge the contribution of my co-authors, my institution, and all those who helped me to complete this study.

\section{Ethical Approval}

This retrospective study has been done according to the institutional ethical standards.

\section{References}

1. Mari G, Deter RL, Carpenter RL, et al. Noninvasive diagnosis by Doppler ultrasonography of fetal anemia due to maternal red-cell alloimmunization. Collaborative group for Doppler assessment of the blood velocity in anemic fetuses. N Engl J Med 2000;342(1):9-14. DOI: 10.1056/NEJM200001063420102.

2. Abbasi N, Johnson J, Ryan G. Fetal anemia. Ultrasound Obstet Gynecol 2017;50(2):145-153. DOI: 10.1002/uog.17555.
3. Oepkes D, Seaward PG, Vandenbussche FPHA, et al. Doppler ultrasonography versus amniocentesis to predict fetal anemia. $\mathrm{N}$ Engl J Med 2006;355(2):156-164. DOI: 10.1056/NEJMoa052855.

4. Nicolini U, Nicolaidis P, Fisk NM, et al. Fetal blood sampling from the intrahepatic vein: analysis of safety and clinical experience with 214 procedures. Obstet Gynecol 1990;76(1):47-53.

5. Mari G, Norton ME, Stone J, et al. Society for maternal-fetal medicine (SMFM) Clinical Guideline\# 8: the fetus at risk for anemia-diagnosis and management. Am J Obstet Gynecol 2015;212(6):697-710. DOI: 10.1016/j.ajog.2015.01.059.

6. Mari G. Middle cerebral artery peak systolic velocity for the diagnosis of fetal anemia: the untold story. Ultrasound Obstet Gynecol Off J Int Soc Ultrasound Obstet Gynecol 2005;25(4):323-330. DOI: 10.1002/ uog.1882.

7. Zimmermann R, Durig P, Carpenter Jr RJ, et al. Longitudinal measurement of peak systolic velocity in the fetal middle cerebral artery for monitoring pregnancies complicated by red cell alloimmunisation: a prospective multicentre trial with intentionto-treat. BJOG an Int J Obstet Gynaecol 2002;109(7):746-752. DOI: 10.1111/j.1471-0528.2002.01314.x.

8. Prefumo F, Fichera A, Fratelli N, et al. Fetal anemia: Diagnosis and management. Best Pract Res Clin Obstet Gynaecol 2019;58:2-14. DOI: 10.1016/j.bpobgyn.2019.01.001.

9. Zwiers C, Lindenburg ITM, Klumper FJ, et al. Complications of intrauterine intravascular blood transfusion: lessons learned after 1678 procedures. Ultrasound Obstet Gynecol [Internet] 2017;50(2):180-186. Available from: https://doi.org/10.1002/ uog.17319.

10. Hannah DM, Tressler TB, Taboada CD. Nonimmune hydrops fetalis due to autosomal recessive hereditary spherocytosis. Case reports in women's health 2017;16:4-7. DOI: 10.1016/j.crwh.2017.09.003.

11. Segel GB. Hereditary spherocytosis. Nelson's Textb Pediatr. 17th ed., Philadelphia, PA: Saunders; 2004. pp. 1620-1621.

12. Yaish HM, Christensen RD, Agarwal A. A neonate with Coombsnegative hemolytic jaundice with spherocytes but normal erythrocyte indices: a rare case of autosomal-recessive hereditary spherocytosis due to alpha-spectrin deficiency. J Perinatol 2013;33(5):404-406. DOI: 10.1038/jp.2012.67.

13. Greer JP, Foerster J, Rodgers GM, et al. Hereditary spherocytosis, hereditary elliptocytosis, and other disorders associated with abnormalities of the erythrocyte membrane. Wintrobe's Clin Hematol. 13th ed., Philadelphia: Lippincott Williams Wilkins; 2014. pp. 722-724.

14. McDaniel J, Cramer S. Congenital dyserythropoietic anemia Type 1: A new variant pathogenic CDAN1 mutation. Blood [Internet] 2015;126(23):4551. DOI: 10.1182/blood.V126.23.4551.4551.

15. Niss O, Lorsbach RB, Buchbinder DK, etal.Congenital dyserythropoietic anemia Type I due to biallelic CDAN1 mutations: Report from the Congenital Dyserythropoietic Anemia Registry (CDAR). Blood [Internet] 2019;134(Supplement_1):3521. DOI: 10.1182/blood-2019128975.

16. Lež C, Fures R, Hrgovic Z, et al. Chorangioma placentae. Rare Tumors [Internet] 2010;2(4):e67-e67. DOI: 10.4081/rt.2010.e67Available from: https://pubmed.ncbi.nlm.nih.gov/21234259.

17. Kodandapani S, Shreshta A, Ramkumar V, et al. Chorioangioma of Placenta: A Rare Placental Cause for Adverse Fetal Outcome. Gbolade BA, Picone O, Piura B, ed. Case Rep Obstet Gynecol [Internet] 2012;2012:913878. DOI: 10.1155/2012/913878.

18. Zanardini C, Papageorghiou A, Bhide A, et al. Giant placental chorioangioma: natural history and pregnancy outcome. Ultrasound Obstet Gynecol 2010;35(3):332-336. DOI: 10.1002/uog.7451.

19. Escribano D, Galindo A, Arbués J, et al. Prenatal management of placental chorioangioma: value of the middle cerebral artery peak systolic velocity. Fetal Diagn Ther [Internet] 2006;21(6):489-493. Available from: https://www.karger.com/DOI/10.1159/000095659.

20. Abdalla N, Bachanek M, Trojanowski S, et al. Placental tumor (chorioangioma) as a cause of polyhydramnios: a case report. Int 
J Womens Health [Internet] 2014;6:955-959. DOI: 10.2147/IJWH. S72178Available from: https://pubmed.ncbi.nlm.nih.gov/25429242.

21. Jones K, Tierney K, Grubbs BH, et al. Fetoscopic laser photocoagulation of feeding vessels to a large placental chorioangioma following fetal deterioration after amnioreduction. Fetal Diagn Ther [Internet] 2012;31(3):191-195. Available from: https://www.karger.com/ DOI/10.1159/000331944.

22. Slaghekke F, Kist WJ, Oepkes D, et al. Twin anemia-polycythemia sequence: diagnostic criteria, classification, perinatal management and outcome. Fetal Diagn Ther 2010;27(4):181-190. DOI: $10.1159 / 000304512$.

23. Simpson LL. Twin-twin transfusion syndrome. Am J Obstet Gynecol 2013;208(1):3-18. DOI: 10.1016/j.ajog.2012.10.880.

24. Gijtenbeek M, Eschbach SJ, Middeldorp JM, et al. The value of echocardiography and Doppler in the prediction of fetal demise after laser coagulation for TTTS: A systematic review and metaanalysis. Prenat Diagn [Internet] 2019;39(10):838-847. DOI: 10.1002/pd.5511Available from: https://pubmed.ncbi.nlm.nih.gov/ 31237967.

25. Sago H, Ishii K, Sugibayashi R, et al. Fetoscopic laser photocoagulation for twin-twin transfusion syndrome. J Obstet Gynaecol Res 2018;44(5):831-839. DOI: 10.1111/jog.13600.
26. Bajoria R, Wee LY, Anwar S, et al. Outcome of twin pregnancies complicated by single intrauterine death in relation to vascular anatomy of the monochorionic placenta. Hum Reprod 1999;14(8):2124-2130. DOI: 10.1093/humrep/14.8.2124.

27. Singh $\mathrm{P}$, Swanson $\mathrm{T}$. Acute and chronic fetal anemia as a result of fetomaternal hemorrhage. Salhan S, Rasmussen S, ed., Case Rep Obstet Gynecol [Internet] 2014;2014:296463. DOI: 10.1155/2014/ 296463.

28. Krywko DM, Jamal Z, Shunkwiler SM, Kleihauer Betke Test. In Treasure Island (FL); 2020.

29. Silver RM, Varner MW, Reddy U, et al. Work-up of stillbirth: a review of the evidence. Am J Obstet Gynecol [Internet] 2007;196(5):433-444. DOI: 10.1016/j.ajog.2006.11.041Available from: https://pubmed.ncbi. nlm.nih.gov/17466694.

30. Bellussi F, Perolo A, Ghi T, et al. Diagnosis of Severe Fetomaternal Hemorrhage with Fetal Cerebral Doppler: Case Series and Systematic Review. Fetal Diagn Ther [Internet] 2017;41(1):1-7. Available from: https://www.karger.com/DOI/10.1159/000446109.

31. Liston R, Sawchuck D, Young D. Fetal health surveillance: antepartum and intrapartum consensus guideline. J Obstet Gynaecol Canada JOGC = J d'obstetrique Gynecol du Canada JOGC 2007; 29(9 Suppl 4):S3-S56. DOI: 10.1016/S1701-2163(16)32615-9. 